\title{
A reexamination of extreme 24-hour rainfall in Louisiana, USA
}

\author{
Gregory E. Faiers, John M. Grymes III, Barry D. Keim, Robert A. Muller
}

Southern Regional Climate Center, Department of Geography and Anthropology, Louisiana State University, Baton Rouge, Louisiana 70803, USA

\begin{abstract}
For the last $30 \mathrm{yr}$ or more, National Weather Bureau Technical Paper No. 40 (TP40) has been the primary document providing design rainstorm magnitudes for the conterminous United States. The primary limitation of this document today is the short periods of record analyzed to determine the design storm estimates. Therefore, this paper reexamines design storms of $24 \mathrm{~h}$ duration in Louisiana using data with much longer periods of record. Results were then compared with frequencymagnitude relationships from TP40. The magnitudes of the storm recurrence intervals were found to differ between the 2 estimations, particularly for the longer durations. Furthermore, greater geographical detail emerged relative to the generalized patterns depicted in TP40.
\end{abstract}

KEY WORDS: Extreme 24-hour rainfall Design rainstorm magnitudes - Louisiana

\section{INTRODUCTION}

The document most frequently referenced for design storm rainfall magnitudes in the United States is U.S. Weather Bureau Technical Paper No. 40 (TP40) (Hershfield 1961). This document, published 32 yr ago, presents generalized patterns of extreme rainfall magnitudes across the country for return periods of up to $100 \mathrm{yr}$ and for durations from 1 to $24 \mathrm{~h}$. However, the age of TP40 and the smooth generalized patterns it displays suggest the need for a more detailed study of rainfall patterns at the regional scale. Furthermore, over half of the data used in TP40 were derived from station records of less than 15 yr. Also, recent concerns over the impact of climate change on the frequency of extreme rainfall events have further generated interest in updating rainfall frequency-magnitude relationships (Huff \& Angel 1990)

High user-demand of this publication has led to other attempts to update extreme $24 \mathrm{~h}$ rainfall information. Recent efforts to address these issues include production of a rainfall recurrence interval (RI) atlas for the Midwest (Huff \& Angel 1992), a TP40 update for West Virginia and Pennsylvania (Zurndorfer 1990), as well as ongoing extreme rainfall studies in the southeast (Changnon et al. 1992) and southwest United
States by the National Weather Service Office of Hydrology.

In 1992, a project to examine extreme rainfall frequency-magnitude relationships in the south central United States was initiated at the Southern Regional Climate Center (SRCC). Many of the initial pilot studies have focused on Louisiana extreme rainfall. Louisiana is an ideal state to study excessive precipitation events because it has the greatest annual precipitation of any of the contiguous United States (NOAA 1988), as well as some of the greatest rainfall magnitudes, according to TP40. Moreover, extreme rainfalls are derived from a variety of mechanisms including convective activity, frontal passages, and tropical storms (Johnson et al. 1987, U.S. Geological Survey 1988, Hirschboeck \& Coxe 1991). In addition, Keim \& Muller (1992) found recent increases in storm magnitudes in the New Orleans area and Hirschboeck \& Coxe (1991) found recent increased frequencies of urban flash-flooding in some cities within the state. Collectively, these factors make Louisiana an interesting state for the study of extreme rainfall. Therefore, the purpose of this study is to reexamine the $24 \mathrm{~h}$ extreme rainfall frequency-magnitude relationships in Louisiana with focus on a comparative analysis between SRCC and TP40 design storm magnitudes. 


\section{DATA AND METHODS}

Long-term daily rainfall records were used to generate the $24 \mathrm{~h}$ frequency-magnitude relationships. Although it would be ideal to extract and analyze $24 \mathrm{~h}$ storms derived from continuous hourly observations, there are many shortcomings to the hourly data. Among these deficiencies are numerous missing observations (many of which occur during extreme events), shorter periods of record than available from the daily series, and a station density lower than the daily network. For these reasons, the sites with the best hourly precipitation data are only used for deriving regional ratios of $24 \mathrm{~h}$ : daily values (Sorrell \& Hamilton 1990, Huff \& Angel 1992).

The primary rainfall records analyzed consist of observational-day totals from each site included in the study. Observational days commonly differ from calendar days in that most daily observations are not made at midnight, but rather in the morning (often at 07:00 or 08:00 $\mathrm{h}$ local time) or in the afternoon (usually at 17:00 h local time). The primary problem associated with daily rainfall data results from the discrete method of recording a continuous process. As a result, daily rainfall data can be unrepresentative of storm rainfalls over a continuous $24 \mathrm{~h}$ period by splitting storm rainfall into 2 observational days. This decreases many of the storm magnitudes in the daily series.

To determine the relationship between observational-day extreme rainfall and extreme $24 \mathrm{~h}$ movingwindow rainfall, it was first necessary to extract the largest $24 \mathrm{~h}$ moving-window rainfall events (sliding in $1 \mathrm{~h}$ increments) from the 14 best sites across the state with hourly data (Fig. 1). These sites were selected

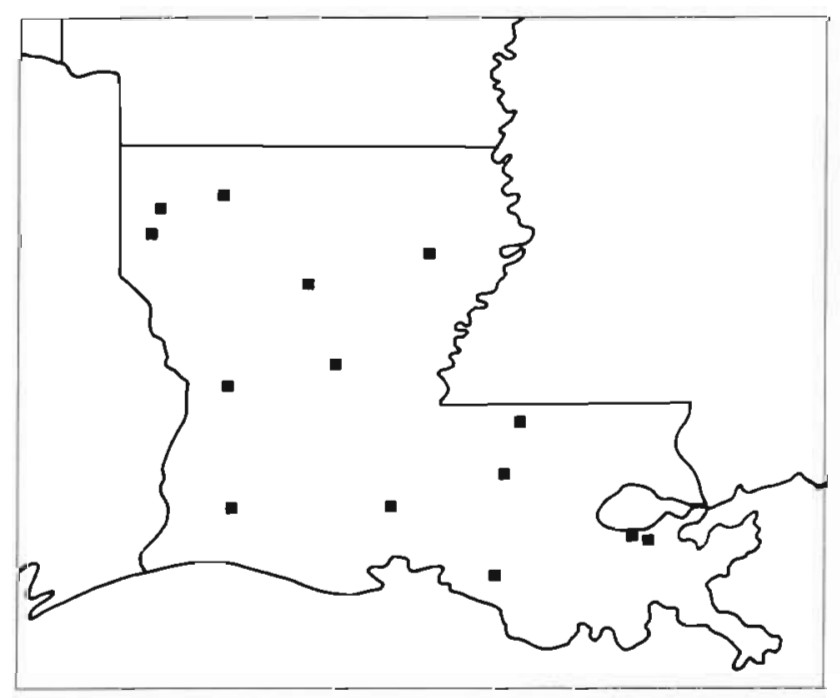

Fig. 1. Louisiana, USA. Hourly precipitation sites used to derive daily and hourly precipitation ratios based upon quality of data (especially with respect to minimizing missing observations) and a length-ofrecord criterion of $20 \mathrm{yr}$ or more. These sites also needed corresponding daily data with which to compare the hourly moving-window amounts. To maintain consistency between the hourly and the daily records at each site, daily events missing in the hourly record were excluded from this phase of the study. The largest $24 \mathrm{~h}$ moving-window values were then included in the partial duration series for each site.

Partial duration series are composed of the largest events which occurred during the period of record, regardless of the year in which they occurred. In this study, the number of storms in the series is equal to the number of years of record at each site. Several storms may be included from one calendar year while other years may have no storms represented in the series. In contrast, an annual series includes only the largest storm from each year, thereby concealing some large storms while including storms of smaller magnitude from 'less active' years. Therefore, the partial duration series is considered to be the most appropriate and accurate in extreme rainfall analyses (Hershfield 1961, Dunne \& Leopold 1978).

Once the partial duration series of $24 \mathrm{~h}$ movingwindow and observational-day events were derived, the data were fit to the Gumbel extreme value probability distribution. The Gumbel distribution was selected because it was the distribution used by Hershfield in TP40 and allows for a reasonably accurate comparison between the 2 studies. The values derived from the $24 \mathrm{~h}$ and daily series were then used to develop ratios to convert abservational daily data to $24 \mathrm{~h}$ moving-window equivalents across the state. The ratios were examined for spatial trends to determine whether regional ratios would be needed, or whether an average ratio for all sites could be applied statewide. Since a cohesive spatial pattern was not evident, it was concluded that one statewide ratio for all RIs was appropriate and the daily storm magnitudes needed to be increased by $13 \%$ to make them equivalent to $24 \mathrm{~h}$. moving-window amounts (Table 1 ). This same adjustment factor was used in TP40 and in the updated atlas for the midwest United States (Huff \& Angel 1992). While no strong geographic patterns were evident across Louisiana, the differences exhibited are intriguing and should be examined when conducting similar studies in other states.

It appears that the time of observation in conjunction with the timing of the most extreme events plays the largest role in determining the local ratios. For example, at Lafayette, the ratios are quite large as the highest storms were split into 2 observational days, while 60 miles $(97 \mathrm{~km})$ to the west, at Lake Charles, the larger storms primarily fell within observational days 
Table 1 Ratios of 24 h moving-window: observational-day values by recurrence interval at selected sites across the study area, Louisiana, USA. N.O.: New Orleans

\begin{tabular}{|lcccccc|}
\hline Locations & \multicolumn{6}{c|}{ Recurrence interval (yr) } \\
& 2 & 5 & 10 & 25 & 50 & 100 \\
\hline Alexandria & 1.11 & 1.09 & 1.08 & 1.08 & 1.07 & 1.07 \\
Baton Rouge & 1.12 & 1.14 & 1.15 & 1.16 & 1.17 & 1.17 \\
Cinton & 1.09 & 1.08 & 1.07 & 1.06 & 1.06 & 1.06 \\
Keithville & 1.14 & 1.14 & 1.15 & 1.15 & 1.15 & 1.16 \\
Lafayette & 1.28 & 1.25 & 1.24 & 1.23 & 1.22 & 1.15 \\
Lake Charles & 1.10 & 1.11 & 1.12 & 1.12 & 1.13 & 1.13 \\
Leesville & 1.10 & 1.13 & 1.14 & 1.15 & 1.16 & 1.16 \\
Minden & 1.13 & 1.15 & 1.15 & 1.16 & 1.16 & 1.17 \\
Morgan City & 1.19 & 1.17 & 1.16 & 1.15 & 1.15 & 1.15 \\
N.O. Audubon & 1.13 & 1.14 & 1.14 & 1.14 & 1.14 & 1.14 \\
N.O. Airport & 1.16 & 1.15 & 1.14 & 1.14 & 1.13 & 1.13 \\
Shreveport & 1.15 & 1.12 & 1.10 & 1.08 & 1.07 & 1.07 \\
Winnfield & 1.00 & 1.08 & 1.12 & 1.15 & 1.17 & 1.18 \\
Winnsboro & 1.07 & 1.12 & 1.13 & 1.15 & 1.16 & 1.17 \\
Mean & 1.13 & 1.13 & 1.14 & 1.14 & 1.14 & 1.14 \\
SD & 0.06 & 0.04 & 0.04 & 0.04 & 0.05 & 0.04 \\
& & & & & & \\
\hline
\end{tabular}

(or between observations) resulting in lower ratios. Examination of such ratios requires caution since region- or statewide-assigned ratio values could disguise true physically induced deviations at particular locations.

After the $24 \mathrm{~h}$ : daily ratio was determined for the state, daily data at over 60 sites in Louisiana and 10 nearby sites (Fig. 2) in adjacent states were used to extract partial duration series of extreme daily rainfalls. In TP40, for comparative purposes, 65 daily precipitation sites and 23 hourly sites were used to derive the magnitude-frequency relationships displayed on the

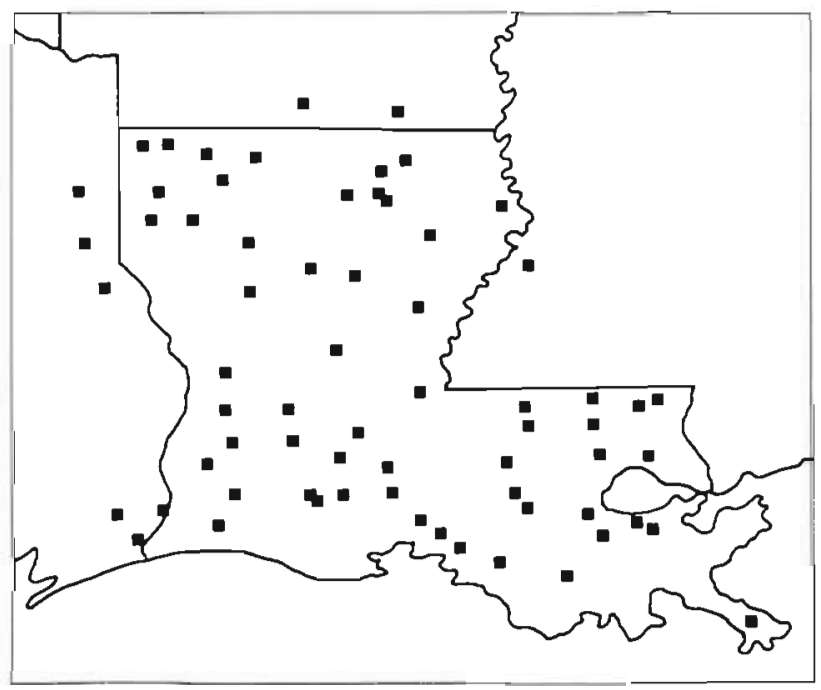

Fig. 2. Louisiana, USA. Daily precipitation sites used to derive extreme rainfall frequency-magnitude relationships maps (see Figs. 3 to 5). Each of these sites in the current study had a period of record of at least $40 \mathrm{yr}$, with 20 of the sites having record lengths in excess of $50 \mathrm{yr}$ (none with a period of record greater than $60 \mathrm{yr}$, while in TP40, nearly half of the station records were 15 yr or less). These data were then fit to the Gumbel distribution and the results increased using the 1.13 adjustment factor. The $24 \mathrm{~h}$ magnitudes for the various RIs were plotted, and isohyets drawn to depict the spatial patterns. The standard errors for each RI were considered to allow for smoothing of the isohyetal lines. These patterns were then compared to TP40.

There are several similarities and differences in the methods employed in this research and TP40. Similarities include the use of daily rainfall records rather than hourly data, the 1.13 adjustment from discrete daily to continuous $24 \mathrm{~h}$, utilization of the Gumbel distribution, similar station densities, and the assumption that storm type does not affect the statistical properties of the extreme events. Differences include an attempt in the SRCC study to identify local and regional detail in the isohyet patterns rather than the large-scale generalizations applied in TP40. In addition, longer periods of record were examined in the SRCC analysis. Also, true partial duration series were used in the SRCC project while annual series (adjusted to partial duration series equivalent) were examined in TP40.

\section{RESULTS AND ANALYSIS}

For display and discussion purposes, the 2, 25, and 100 yr storm values from the SRCC study and TP40 were examined. Patterns of the 5, 10, and 50 yr storms are transitional between the RIs displayed in this paper. Estimates of extreme rainfall associated with RIs which extend beyond the number of years of record are highly suspect and potential inaccuracies are recognized (Huff \& Angel 1992). However, 100 yr storm recurrence interval estimates are implemented in engineering design and provide useful, but limited, information.

Fig. 3 displays the SRCC, TP40, and departure (SRCC:TP40) maps for the 2 yr storm RIs. Note the more generalized pattern in the map prepared by Hershfield (1961) as well as the location of the maximum and minimum values. In these maps, there also is a difference in isohyet intervals, with the TP40 intervals set at $1 / 2$ inch while the SRCC intervals are 1 inch ( 1 inch $=25.4 \mathrm{~mm}$ ). In TP40 the highest values are found in the Mississippi River delta with the smallest magnitudes having a tendency to be in the northeast. By comparison, the SRCC map has maximum values in the southwestern corner of the state (a pattern which is 

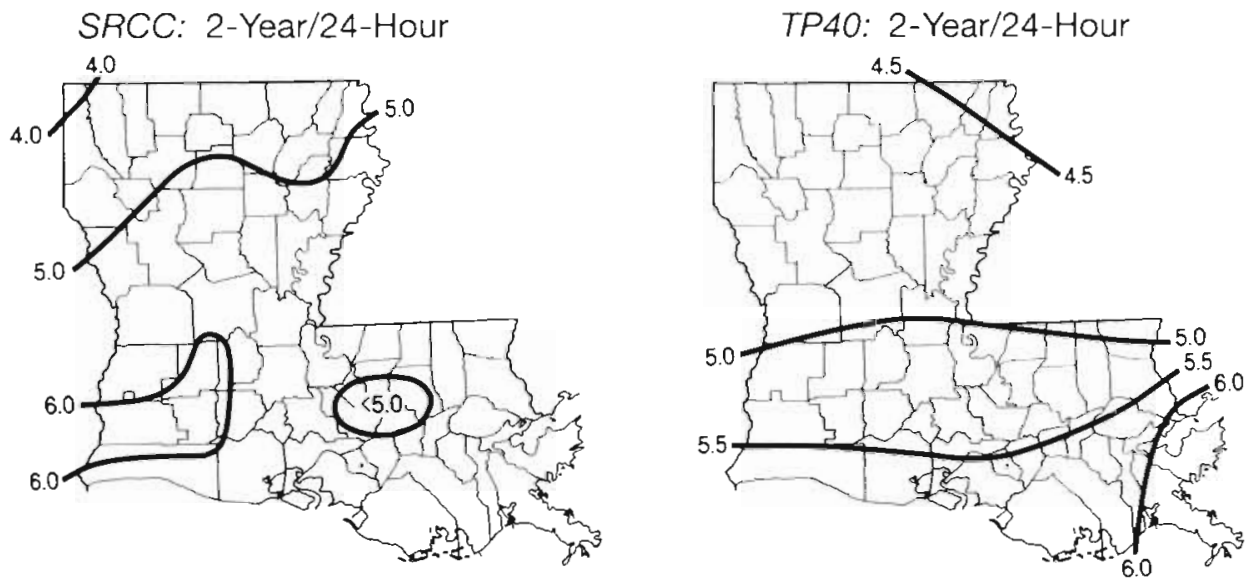

\section{2-Year/24-Hour STORM (SRCC:TP40)}

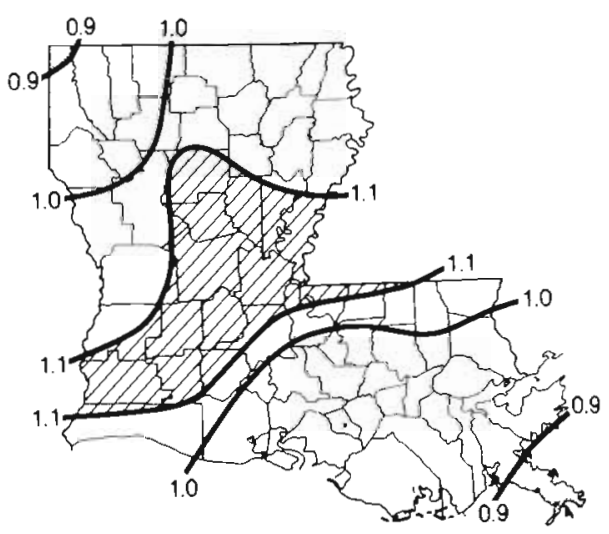

repeated for all RIs). These high values are supported by equally large estimates in adjacent southeastern Texas. The lowest values in the SRCC maps are generally found in the northwest. Also note the northward extension of higher values through the central part of Louisiana in the SRCC map; this tendency becomes even more apparent in the longer RIs.

Another anomalous pattern emerging in the SRCC maps is centered northwest of New Orleans, near Baton Rouge, where 2 yr storm values are less than 5 inches. In general, this area north and northwest of New Orleans tends to have anomalously low values through all RIs. Ratios of 1.1 or greater (where SRCC > TP40) at the 2 yr RI form a belt from the southwestern part of the state to the northeast. Ratios of 0.9 or less (SRCC $<\mathrm{TP} 40)$ are found in the southeast and northwest corners of the state.

The southwest-northeast belt of higher ratios in the SRCC maps may be explained in part by the tendency for fronts to become quasi-stationary across this region. Cyclogenesis often occurs in the western. Gulf of Mexico and these storms often track northeastward across the state (Elliott 1949, Saucier 1949, Hsu 1988). Furthermore, slow-moving fronts with this orientation
RATIOS

$$
\begin{aligned}
& 0.8-0.9 \\
& 0.91-1.09 \\
& 1.10-1.19
\end{aligned}
$$

Fig. 3. Louisiana, USA: maps of $24 \mathrm{~h}$ storm values (in inches of rainfall) with $\mathrm{RI}=2 \mathrm{yr}$, derived by the SRCC and TP40, and the differences between them as expressed by the ratio of SRCC: TP 40 magnitudes

represent the most common surface synoptic pattern associated with flash flooding in the state (Hirschboeck \& Coxe 1991).

The smaller ratios in the Mississippi River delta illustrated in the SRCC map are not surprising because this area, virtually surrounded by water, would be less susceptible to excessive rainfall as stabilizing maritime influences suppress convection. Hershfield, in preparing TP40, apparently used one station (Burrwood) in this area and considered the values here to be among the greatest in the entire contiguous United States. Furthermore, it has been concluded that a 25.56 inch, $24 \mathrm{~h}$ rainstorm appearing in the Burrwood hourly record (March 6, 1948) is erroneous and may have been incorporated into Hershfield's analysis. No other nearby sites had notable rainfall amounts on or near this date and no newspaper accounts made note of any unusual rainfall in the lower Mississippi River delta at this time. Also, the exposure of the delta to tropical storms may have encouraged the decision to establish higher values in this region.

Lower ratios in the northwest are consistent throughout the RIs and are compatible with annual average rainfall patterns which are also low in this area relative 
to the remainder of the state. The northwest corner of Louisiana is the most continental section of the state as moisture-flow from the Gulf of Mexico is more limited than in areas to the south and east. Overall, at the 2 yr $\mathrm{RI}$, the SRCC values are equal to or above those of TP40 in about half of the state with only a very small percentage of the state possessing ratios of 0.9 or less.

At the 25 yr RI (Fig. 4), the TP40 patterns are consistent with those established at the 2 yr RI. By contrast, the SRCC map accentuates the southwest-northeast orientation of the maximum values with an additional northward extension. The anomalously low values in the area north and northwest of New Orleans are again present in the SRCC map while the New Orleans metropolitan area becomes a region of anomalously high values. Ongoing research at the SRCC has found that this New Orleans maximum is likely the result of urban-enhanced rainfall, a finding supported by the previous work of Huff \& Changnon (1973). For the sake of simplicity, the New Orleans enhancement is not displayed in the departure maps due to the proximity of ratios less than 1 to the northwest and southeast. Unfortunately, the processes behind the anomalously low values north and northwest of New Orleans are not well understood and will require further research. The decrease in rainfall intensities in this region could be related to stabilizing influences of Lake Pontchartrain and/or associated surface speed divergence. These regional anomalies, however, are supported by several stations at all RIs.

The departure map for the 25 yr storm shows that, again, a little over half of the state has ratios of 1.0 or greater. However, ratios equal to or less than 0.9 now represent almost a third of the state, primarily focused on the 3 areas previously cited (Mississippi River delta, the northwest corner of the state, and the area north and northwest of New Orleans).

At the 100 yr RI (Fig. 5), the TP40 maps again show maximum values in the Mississippi River delta with minima in the northeast and smooth generalized isohyets between these extremes. The SRCC map maintains the previously described patterns including the New Orleans urban anomaly and the southwestern maxima. At the 100 yr RI, the ratios are 1.0 or greater in under half of the state while the spatial coverage of ratios of less than 1.0 is at its greatest extent. Only a
SRCC: 25-Year/24-Hour

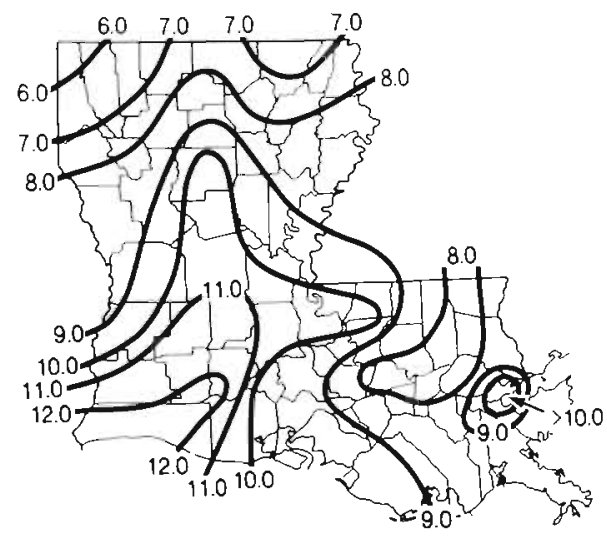

TP40: 25-Year/24-Hour

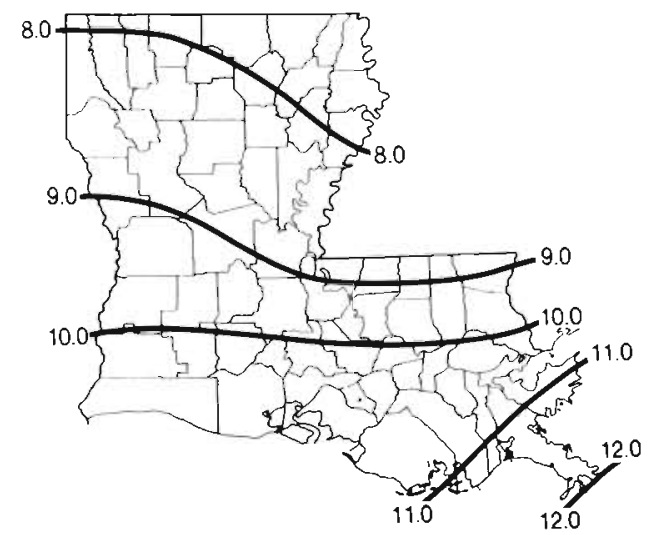

25-Year/24-Hour STORM (SRCC:TP40)

Fig. 4. Louisiana, USA: maps of 24 h storm values (in inches of rainfall) with $\mathrm{RI}=25 \mathrm{yr}$, derived by the SRCC and TP40, and the differences between them as expressed by the ratio of SRCC:TP40 magnitudes

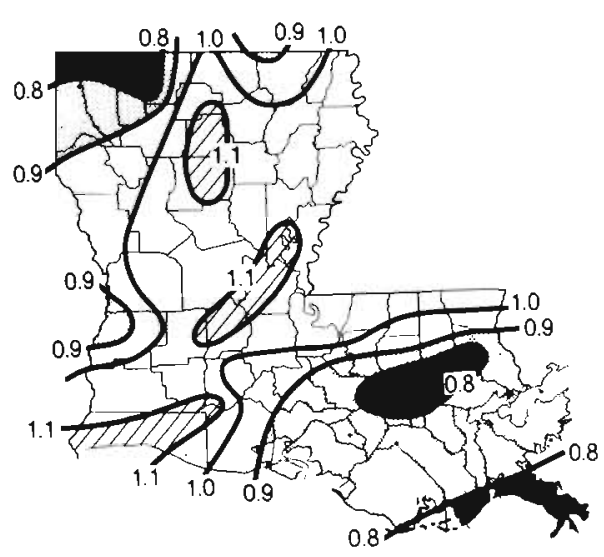

RATIOS

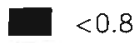

$0.8-0.9$

$0.91-1.09$

$1.10-1.19$ 
SRCC: 100-Year/24-Hour

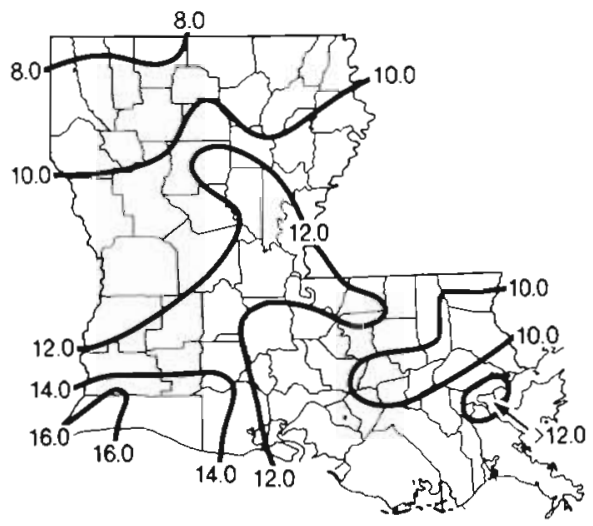

TP40: 100-Year/24-Hour

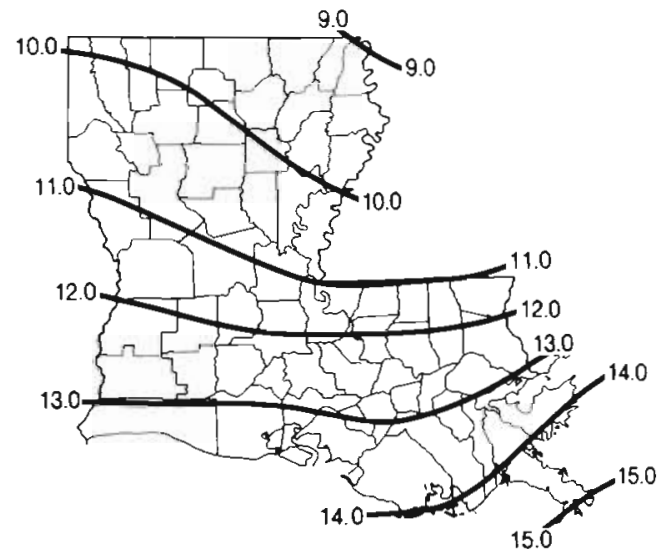

100-Year/24-Hour STORM (SRCC:TP40)

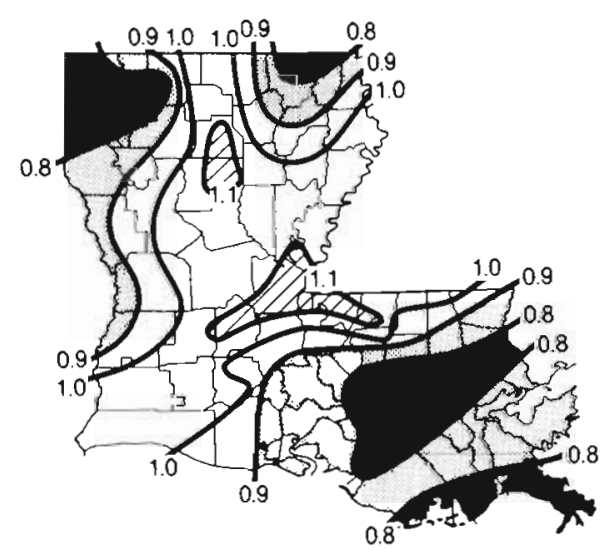

small percentage of the state has ratios of 1.1 or more than those projected in TP40. As previously stated, caution should be taken when considering $100 \mathrm{yr}$ storm values because these estimates extend well beyond the period of record at all sites.

\section{CONCLUSIONS}

The storm magnitudes and patterns displayed in the updated SRCC maps vary from those prepared by Hershfield in TP40, especially for the longer RIs. In $\mathrm{TP} 40$, the maximum values for Louisiana occur in the southeast and minimum values are found in the northeast. The SRCC maps, however, depict maxima and minima in the southwest and northwest, respectively. The locations of extreme high and low values in the SRCC maps, i.e. New Orleans urban area and the delta region south of New Orleans, are better supported by known precipitation-inducing mechanisms than are the regions of maxima and minima indicated in TP40
RATIOS

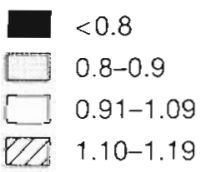

Fig. 5. Louisiana. USA: maps of 24 h storm values (in inches of rainfall) with $\mathrm{RI}=100 \mathrm{yr}$, derived by the SRCC and TP40, and the differences between them as expressed by the ratio of SRCC:TP40 magnitudes

The generalized patterns of TP40 also differ from those found in the SRCC product. These differences were intentional and reflect the design purposes of both projects. TP40 was produced on a national scale while the SRCC research is regional. The regional scale of this project, therefore, allowed for greater detail in an attempt to depict physically induced local- to regional-scale anomalies.

There is greater confidence in the SRCC results, principally due to the longer period of record employed in the SRCC product. It is interesting to note that despite the increase in record length used to produce the SRCC maps, there does not appear to be any physically related increase in extreme rainfall in the state. The major differences in the maps are not in the magnitudes but in the geographic patterns of extreme rainfall in Louisiana.

Acknowledgements. The authors thank Chi Nguyen, Liyun Ye, Youngeun Choi, Keith Henderson and Kevin Robbins for their technical assistance and Mary Lee Eggart. for drafting the figures. This research was funded by NOAA grant number NA908A-D-CP775 


\section{LITERATURE CITED}

Changnon, D., Lawson, C., Jacobson, J., Smith, D. J. (1992) Initial results from analyses of large precipitation events. Southeast Clim. Rev. 3: 3-11

Dunne, T., Leopold, L. B. (1978). Water in environmental planning. W. H. Freeman \& Company, San Francisro

Elliott, R. D. (1949). Forecasting the weather - the weather types of North America - 5. Weatherwise 2: 110-113

Hershfield, D. M. (1961). Rainfall frequency atlas of the United States. Weather Bureau Technical Paper 40, U.S Department of Commerce, Washington, DC

Hirschboeck, K. K., Coxe, M. F. (1991). Identification of highrisk atmospheric and surface conditions for urban flash flooding in Louisiana. Louisiana Water Resources Institute, Baton Rouge

Hsu, S. A. (1988). Coastal meteorology. Academic Press, San Diego

Huff, F. A., Angel, J. R. (1990). Fluctuations in the frequency distributions of heavy rainstorms in the Midwest. Preprint, American Meteorological Society symposium on global change systems, Boston

Huff, F. A., Angel, J. R. (1992). Rainfall frequency atlas of the Midwest. Midwest Climate Center, Bulletin 71, MCC Research Report 92-03, Champaign, IL

Huff, F. A., Changnon, S. A. (1973). Precipitation modification by

Editor: V. Meentemeyer, Athens, Georgia, USA major urban areas. Bull. Am. Meteorol. Soc. 54: 1220-1232

Johnson, G. A., Mortimer, E. B., Lau, H. W. N. (1987). Synoptic climatology of heavy rainfall events in Louisiana. Preprint, American Meteorological Society Seventh Conference on Hydrometeorology, Boston

Keim, B. D., Muller, R. A. (1992). Temporal fluctuations of heavy rainfall magnitudes in New Orleans, Louisiana: 1871-1991 Water Resour. Bull. 28: 721-730

NOAA (National Oceanic and Atmospheric Administration) (1988). State, regional and national monthly and annual precipitation weighted by area for the contiguous United States, January 1931-December 1987 Historical Climatology Series 4-2. National Climatic Data Center, Asheville, NC

Saucier, W. J. (1949). Texas west-Gulf cyclones. Mon Weather Rev. 77: 219-231

Sorrell, R. C., Hamilton, D. A. (1990). Rainfall frequency for Michigan, 24-hour duration with return periods from 2 to 100 years. Unpubl. report, Michigan Department of Natural Resources, Lansing, MI

U.S. Geological Survey (1988). National water summary 1988 : floods and droughts. USGS water supply paper 2375 . U.S. Geological Survey, Springfield, VA

Zurndorfer, E. A. (1990). Assessing the effects of additional data on precipitation frequency analyses in the United States. Preprint, American Meteorological Society 6th Conference on Applied Climatology, Boston

Manuscript first received: July 28, 1993

Revised version accepted: November 15, 1993 